\section{Orchid-Consortium deal}

Orchid BioSciences (Princeton, NJ) announced a deal in July to score the prevalence of 60,000 single nucleotide polymorphisms (SNPs) identified by the SNP consortium. By performing 7.2 million SNP genotypes, Orchid will determine the allelic frequency of the SNPs from 120 patients of diverse ethnicity-information that the consortium will make publicly available as it emerges. Pharmaceutical companies will be able to use this data to see whether a particular SNP is rare, uniform across ethnicities, or prevalent in one particular group. "This set of SNPs, with this frequency data, will serve as the backbone for the high density SNP map and really serve as a prerequisite for identifying medically useful SNPs," says Dale Pfost, Orchid's president and CEO. Financial details were not disclosed; however, the commercial opportunity for Orchid, according to Pfost, is to format the SNPs and produce kits of content-rich SNP panels ready for pharmaceutical and medical research correlating SNPs with certain diseases and responses to drugs.

\section{Singapore genome program}

The Singaporean government has launched a $\$ 570$ million program to promote life sciences $R \& D$ and encourage private investment in Singapore. The initiative, announced on June 26, includes a five-year, $\$ 34$ million project to analyze genetic variations in the Singaporean population, which comprises Malay, Indian, and Chinese people. The project also plans to study the genetic basis of diseases common in Singapore, such as breast and liver cancer, and develop personalized medicine for the Asia-Pacific population. The data will be publicly available, and the government, which will invest in biotechnology startups, hopes international life sciences companies will collaborate on projects in the country.

Singapore has the second largest economy in Southeast Asia, after Hong Kong, and its life sciences industry grew $60 \%$ last year (from $\$ 2.3$ billion to $\$ 3.6$ billion). However, critics say it lacks the infrastructure needed to support further growth and in order to do so must secure qualified researchers from overseas.

Business and Regulatory News Briefs written by Julie Grisham, John Hodgson, Eric Niiler, Debra Robertson, and Asako Saegusa.

\section{CAT's phage technology patent upheld}

The Opposition Division of the European Patent Office (EPO; Munich) has upheld Cambridge Antibody Technology's (CAT; Melbourn, UK) core "McCafferty" European patent (EP 0589877) without amendments following a challenge from rivals Dyax (Cambridge, MA), BioInvent (Lund, Sweden), and Morphosys (Munich); the patent covers methods for making single-chain variable-region fragments on certain bacteriophages. The legal path is now cleared for the recommencement of CAT's feud with Morphosys; proceedings that CAT had taken out against Morphosys in the Munich District Court for infringement of both the McCafferty patent and a broader phage display patent known as "Winter II" had been suspended, pending the EPO Opposition Division's decision. Morphosys Chief Scientific Officer Thomas von Rüden insists that the EPO decision does not affect its ability to develop and use its HuCAL library even though $\mathrm{HuCAL}$ does involve the use of phage in screening for appropriate antibody regions. However, CAT CEO Dave Chiswell is reportedly equally insistent that its rivals could not display singlechain variable-region fragments without infringing the CAT patent.

$J H$

\section{Celgene buys Signal}

Celgene (Warren, NJ), a developer of chirally pure drugs, agreed on June 30 to purchase gene-regulation firm Signal Pharmaceuticals (San Diego, CA) for \$200 million in an allstock deal. Both companies are working on drugs to treat cancer and inflammation, but Celgene has successfully exploited commercial applications of a pre-existing drug (thalidomide), while Signal has several drugs in the pipeline but none producing revenue. "It's a good match for Celgene," says Caroline Copithorne, biotechnology analyst at Morgan Stanley Dean Witter (San Francisco), "They haven't had a basic science drug-discovery engine, which is what Signal brings to the table."

Celgene shares, 3.7 million of which will be issued to Signal's owners, rose $\$ 5.37$ to $\$ 58.87$ on the day of the announcement.

Signal, which last year lost $\$ 7.9$ million on revenues of $\$ 11.9$ million, had hoped to raise $\$ 80.5$ million through an initial public offering earlier this year, but decided to withdraw because of the dip in biotech stock prices.

\section{GMO roundup}

- At the Congressional Hunger Center Biotech Briefing in Washington, DC, on June 29, Mae-wan Ho-the Open University lecturer behind the anti-GM "Open Letter from World Scientists to All Governments Concerning Genetically Modified Organisms (GMOs)"-argued against the need for GM crops for developing countries on the basis that "world population figures have been wildly exaggerated." She stated that "By mid-1998, the UN's estimate was that world population will peak at 7.7 billion in 2040 , then go into long-term decline to 3.6 billion by 2150 ." Ho clearly prefers the UN's "low fertility" assumptions whereby global fertility rates are between 1.35 and 1.6 children per woman-rates seen currently in some parts of Eastern and Western Europe (the US rate is 1.99). The UN itself calls its "medium fertility" assumptions "the most likely": These would lead to a 2050 population of 9.4 billion and a 2150 population of 10.8 billion. High-end UN projects put the 2150 world population at between 18 and 27 billion.

- Under the guise of "restoring confidence in [the] GMO approval process," on July 13 the European Commission (EC; Brussels, Belgium) announced plans for a strategy to resume the authorization process for GMOs in Europe on the basis of a "reinforced framework for approvals." That doesn't mean, of course, that authorizations will resume-only the process will, and the hurdles for authorization will be higher. Implicit is that a huge amount of administrative time will be deployed-first at the EC and then within the EU member states-in putting in place the EC's strategy: 1) A comprehensive set of labeling provisions that would cover GMOs and GMO products will be submitted by the EC by autumn 2000. (Subtext: make sure that products such as oils containing no DNA or protein clues as to their GM origins nevertheless have to be nonsensically labeled). 2) An initiative on a traceability system for GMOs to be submitted by the EC by autumn 2000. (Subtext: impose a tax on GM products by insisting on a paper or electronic trail overseen by officials from seed to shopping mall).

3) Accelerate work on environmental liability, long-term effects on biodiversity and international development. (Subtext: ensure that further hurdles remain even after labeling and traceability have been added to the more traditional product requirements of safety and quality). $\quad J H$ 